\title{
Reaction to Letter from Zhang et al.
}

We are all aware of the outbreak of the new coronavirus (2019-nCoV) in China, particularly in Wuhan city and Hubei province. Recent updates have shown that infections are now on the rise on a worldwide scale [1], with an increasing number of cases in certain parts of Europe. Realizing that 2019-nCoV is starting to knock on our doors, we decided to publish this letter from Dr. Zhang and colleagues because it clearly and concisely summarizes important measures that need to be taken to prevent 2019-nCoV transmission in a hospital setting. It is reassuring that medical authorities under the supervision of the World Health Organization have taken and will continue to take dedicated measures aimed at minimizing further spread of 2019-nCoV among the general population but also among those that risk their lives when taking care of patients that have meanwhile been infected.

On behalf of the Editorial team,

Peter D. Siersema, Editor-in-Chief

\section{Competing interests}

The authors declare that they have no conflictof interest.
The author

\section{Peter D. Siersema}

Department of Gastroenterology and Hepatology, Radboud University Medical Center, Nijmegen, The Netherlands

\section{Corresponding author}

\section{Prof. Dr. Peter D. Siersema}

Department of Gastroenterology and Hepatology, Radboud University Medical

Center, Geert Grooteplein Zuid 10, 6525 GA Nijmegen, The Netherlands

peter.siersema@radboudumc.nl
Reference

[1] Coronavirus COVID-19 Global Cases by Johns Hopkins CSSE. Available from: Accessed: 29 February 2020 https://www.arcgis. com/apps/opsdashboard/index.html\#/ bda7594740fd40299423467b48e9ecf6

\section{Bibliography}

DOI https://doi.org/10.1055/a-1128-9681 Endoscopy 2020; 52: 315-315

(c) Georg Thieme Verlag KG

Stuttgart $\cdot$ New York ISSN 0013-726X 